\title{
USE OF WEAK ION ASSOCIATION IN THE SEPARATION OF INORGANIC ANIONS BY CAPILLARY ELECTROPHORESIS WITH SPECIFIC APPLICATION TO SIMULTANEOUS-TRACE DETERMINATION OF BROMATE AND IODATE IN DRINKING WATER
}

\author{
Julius Mbuna $^{1 *}$, F.N. Ngassapa ${ }^{1}$, and Shoji Motomizu ${ }^{2}$ \\ ${ }^{1}$ Chemistry Department, Faculty of Science, Dar es Salaam University College of Education, P. O. \\ Box 2329, Dar es Salaam, Tanzania \\ ${ }^{2}$ Department of Chemistry, Faculty of Science, Okayama University, 3-1-1 Tsushimanaka, \\ Okayama 700-8530, Japan
}

(Received January 22, 2007; revised March 28, 2007)

\begin{abstract}
In this work weak ion association was used to effect selectivity and detection of inorganic anions with environmental or health significance by capillary electropheresis, CE. Tetrabutylammonium ion was used as a pairing anion to separate mixtures containing closely or co-migrating inorganic anions at pHs 3.8 and $\mathrm{pH} 7$. Despite taking a longer analysis time, better resolution is achieved at $\mathrm{pH} 7$ than 3.8. Trace level of bromate and iodate present in drinking water were determined after online pre-concentration by field enhanced sample injection (FESI) technique. Consequently an internal standard $\left(\mathrm{SCN}^{-}\right)$was employed, which entailed the use of tetrabutylammonium ion as a pairing cation to resolve the internal standard from a co-migrating broad peak. The LODs $(\mathrm{S} / \mathrm{N}=3)$ were $7.8 \times 10^{-10} \mathrm{M}(10 \mathrm{ppb})$ and $1.2 \times 10^{-9} \mathrm{M}(0.21 \mathrm{ppb})$ for bromate and iodate, respectively. The method was subsequently used to determine bromate and iodate levels in drinking water.
\end{abstract}

KEY WORDS: Weak ion association, Selectivity, Capillary electrophoresis, Tetrabutylammonium ion, Bromate, Iodate, Drinking water

\section{INTRODUCTION}

Identification and quantification of inorganic anions find significant applications in several areas including forensic investigations, medicine, monitoring of environment pollution and quality/safety control of water, foods and pharmaceuticals. This is because inorganic anions may constitute a component or residue of explosives or poisons [1], illicit drugs [2] or biological/ environmental specimens [3]. Certain patient's conditions or diseases can be diagnosed on the basis of inorganic anion content, e.g. thiocyanate levels in urine or serum may reveal the health status of the patient or consumption pattern of certain prescribed drugs [4]. In addition, to monitor levels of toxic or health endangering chemical species contained in water, foods and pharmaceuticals, constant monitoring of some inorganic anions, e.g. nitrite, bromate, thiocyanate, chromate [5] by manufacturers and the regulating authorities, is imperative.

Since these anions often occur as traces in extremely complex matrices, accurate identification and quantification is challenging, thereby making selectivity extremely important. In CE, selectivity of anions can be achieved in a number of ways, including manipulation of the background electrolytes parameters [6]; use of electroosmotic flow, eof modifiers like surfactants [7]; complex formation [8, 9]; addition of organic solvents or their binary aqueous mixtures to Background electrolyte, BGE or buffer [10, 11]; and ion association [12-14]. However, for the separation of inorganic anions, significant changes in selectivity can be achieved by ion association or addition of an organic solvent to the migrating buffer/ electrolyte or a combination of the two strategies. Studies on strong ion association between quaternary ammonium and aromatic ions [15]; metal ions with crown ethers and metalpyridylazoresorcinolato with quaternary ammonium ions [16], nonionic surfactants and

*Corresponding author. E-mail: jmbuna@duce.ac.tz 
polyethylene glycol [17] have already been reported. Compared to strong ion association, weak ion association, which involves interaction between tetraalkylammonium ammonium ions and small inorganic anions has received less attention.

In this work, the potential use of weak ion association to effect selectivity of either comigrating or closely migrating inorganic anion by using tetrabutylammonium ion, $\mathrm{Bu}_{4} \mathrm{~N}^{+}$, as a pairing cation is illustrated. Mixtures of inorganic anions of environmental interest were separated by weak ion association at $\mathrm{pH} 3.8$ and $\mathrm{pH} 7$ using formate and phosphate buffers, respectively. Subsequently, a CE method for trace level determination of bromate and iodate, incorporating ion association was developed.

Bromate is one of the disinfection by-products (DBP's) formed during the disinfection of drinking water supplies against potentially harzadous microorganisms. Among the inorganic DBP's, bromate is of special interest because it is classified as an animal carcinogen [18] and a probable human carcinogen by the International Agency for Research on Cancer [19, 20]. Bromates are formed during the disinfection by hypochlorite $\left(\mathrm{OCl}^{-}\right)$[21] for municipal water supplies or ozonolysis for some bottled drinking water [22]. Although the maximum contaminant level (MCL) for bromate set by the Environmental Protection Agency, EPA is 10 $\mu \mathrm{g} / \mathrm{L}$, a lifetime consumption of $5.0 \mu \mathrm{g} / \mathrm{L}$ poses a potential cancer risk [23]. As a result highly sensitive methods for routine bromate analysis are urgently required.

Bromate in solutions has been determined mainly by ion chromatography (IC), which is a popular technique for inorganic anion determination especially for trace level analysis. EPA recommends IC methods as the only acceptable methods for bromate determination [24]. Despite efforts to simplify the experimental procedure and overcome several technical problems, the IC method requires chromatographic expertise to perform. Furthermore, the analysis time is long ( 25 minutes per sample) and requires three separate cartridges to remove the interfering ions. CE compliments ion chromatography but is preferred in inorganic anions determination, because of its simplicity in method development, less wastage of reagents and high efficiency coupled with lower equipment acquisition costs. Thus, there is a need to develop CE methods for bromate determination, which are easy to carryout and require no special post column reagents.

Online pre-concentration is a pre-requisite for trace determination of the analyte of interest. Of the two online CE pre-concentration techniques, viz., stacking and sweeping, stacking is more suitable for inorganic anions' concentration because sweeping is dependent on partitioning of analytes into pseudostationary phase of the surfactant, which is not effective for the small inorganic anions. Pre-concentration was done by Field Enhanced Sample Injection (FESI) because Large Volume Sample Stacking (LVSS) failed to concentrate bromate below $10^{-6} \mathrm{M}$ level. Since the sample had to be introduced electrokinetically, internal standard method had to be used. $\mathrm{SCN}^{-}$was chosen as an internal standard because it migrates after a large peak suspected to be nitrate's and is commercially available in pure form. To resolve the closely migrating peaks ( $\mathrm{SCN}^{-}$and the large peak), $\mathrm{Bu}_{4} \mathrm{~N}^{+}$was used.

The aim of this work was to demonstrate the use of weak ion association in separating inorganic anions and apply weak ion association to simultaneous determination of trace levels of bromate and iodate in real drinking water samples. 


\section{EXPERIMENTAL}

\section{Reagents}

All the reagent solutions were prepared using 18.0 M $\Omega \mathrm{cm}$ Milli-Q Labo water (Nihon Millipore, Tokyo, Japan) and filtered through $0.45 \mu \mathrm{m}$ syringe driven filters (Advantec, Tokyo, Japan) before use.

Both formate $(\mathrm{pH} 3.8)$ and phosphate $(\mathrm{pH}$ 7.0) stock buffers contained equimolar amounts $(0.15 \mathrm{M})$ of formic acid/sodium formate and sodium dihydrogen phosphate/disodium hydrogen phosphate, respectively. Formic acid, sodium formate, sodium dihydrogen phosphate, disodium hydrogen phosphate and ethanol (HPLC grade) were purchased from Wako Pure Chemicals, Osaka, Japan.

Cetyltrimethylammonium ion $\left(\mathrm{CTA}^{+}\right)$and tetrabutylammonium ion, $\mathrm{Bu}_{4} \mathrm{~N}^{+}$, as a chloride salt (Tokyo Kasei, Tokyo, Japan) were dissolved in water to make $0.10 \mathrm{M}$ stock solutions. Stock solutions $(0.01 \mathrm{M})$ of the individual anions $\left(\mathrm{Br}^{-}, \mathrm{NO}_{3}^{-}, \mathrm{NO}_{2}^{-}, \mathrm{SCN}^{-}, \mathrm{I}^{-}, \mathrm{S}_{4} \mathrm{O}_{6}{ }^{2-}, \mathrm{BrO}_{3}^{-}, \mathrm{IO}_{3}^{-}\right)$were prepared by dissolving their respective sodium salts (Wako Pure Chemicals, Osaka, Japan) in Milli-Q water. The sample solution consisted of several anions, each diluted to $3 \times 10^{-4} \mathrm{M}$. For trace analysis, iodate and bromate stock solutions were further diluted to $10^{-8} \mathrm{M}$ range prior to measurement.

\section{Apparatus}

All the electrophoretic separations of the anions were done by a Hewlett Packard ${ }^{3 \mathrm{D}} \mathrm{CE}$ system (Waldbronn, Germany) equipped with a diode array detector. The vials compartment of the CE system is fitted with a water-circulating thermostatic device for maintaining constant temperature $\left(25^{\circ} \mathrm{C}\right)$. Electrophoresis was carried out in a $50 \mu \mathrm{m}$ i.d., $375 \mu \mathrm{m}$ o.d., $40 \mathrm{~cm}$ effective length and $48.5 \mathrm{~cm}$ total length, ordinary fused silica capillary (Agilent Technologies, Germany). In experiments demonstrating the ability of ion association to separate anions, samples were hydrodynamically introduced (50 mbar for $3 \mathrm{~s}$ ) and separated by applying a voltage of $-20 \mathrm{kV}$. FESI was used for online pre-concentration in the trace determination of bromate and iodate. Except for trace determination of bromate and iodate which was done at $200 \mathrm{~nm}$, all the anions were detected at $214 \mathrm{~nm}$. System control, signal processing, and data collection were done by HP Chemstation software.

\section{Experimental procedure}

The silica capillary was conditioned with $1 \mathrm{M} \mathrm{NaOH}$ solution for 15 min followed by $0.1 \mathrm{M}$ $\mathrm{NaOH}$ solution for $5 \mathrm{~min}$, then MilliQ water for $5 \mathrm{~min}$ and finally the migrating solution for 5 min. In between runs, the capillary was flushed with $0.1 \mathrm{M} \mathrm{NaOH}(3 \mathrm{~min})$ then water $(3 \mathrm{~min})$ and finally the migrating solutions $(3 \mathrm{~min})$ to ensure reproducibility.

\section{RESULTS AND DISCUSSION}

\section{(a) Resolution of inorganic anions using weak ion association}

Despite ion association being the main mechanism for creating/enhancing anions selectivity in this study, some organic solvents were added where necessary to refine selectivity. Based on previous works $[13,14]$, tetrabutylammonium ion $\left(\mathrm{Bu}_{4} \mathrm{~N}^{+}\right)$was selected as a suitable pairing cation. 
(i) Separation of thiocyanate and thionate ions

As shown in Figure 1a, $\mathrm{SCN}^{-}$and $\mathrm{S}_{4} \mathrm{O}_{6}{ }^{2-}$ migrate closely under the experimental conditions. However, addition of $30 \mathrm{mM} \mathrm{Bu} \mathrm{N}^{+}$to the $\mathrm{BGE}$ completely resolved the two anionic species (Figure $1 \mathrm{~b}$ ). Although fairly distinct peaks start to appear at lower $\mathrm{Bu}_{4} \mathrm{~N}^{+}$concentration (15 $\mathrm{mM}$ ), optimal separation occurs at $30 \mathrm{mM}$. Figure $1 \mathrm{~b}$ suggests that $\mathrm{S}_{4} \mathrm{O}_{6}{ }^{2-}$ associates more strongly with $\mathrm{Bu}_{4} \mathrm{~N}^{+}$than $\mathrm{SCN}^{-}$and is therefore comparatively slowed down. The higher interaction between the $\mathrm{S}_{4} \mathrm{O}_{6}{ }^{2-}$ and $\mathrm{Bu}_{4} \mathrm{~N}^{+}$may partly be due to the comparatively higher charge of the tetrathionate compared to thiocyanate ion. It has been proposed that ionic strength [6] may be used to separate ions of different charge. However, since there is only a small difference in charge between the two anions, using a high ionic strength is not likely to lead to a complete resolution of the two analytes. To the contrary, higher ionic strength is more likely to produce Joule heating effect.

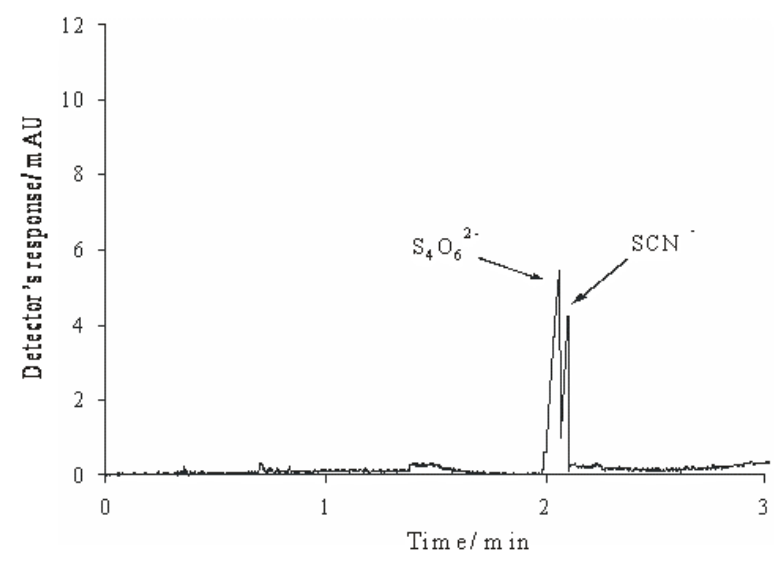

(a)

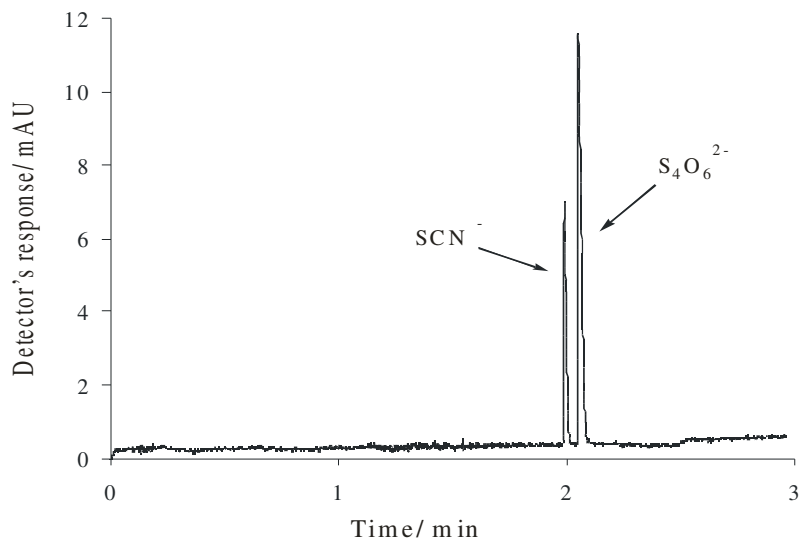

(b)

Figure 1.Co-migration and the resolution of thionate and thiocyanate in the background electrolyte containing (a) formate buffer $(10 \mathrm{mM})$ and (b) formate buffer $(10 \mathrm{mM})$ and $\mathrm{Bu}_{4} \mathrm{~N}^{+}(30 \mathrm{mM})$. Conditions: hydrodynamic injection $(50 \mathrm{mbar}$ at $3 \mathrm{~s}) ;-20 \mathrm{kV}$ potential; detection: $214 \mathrm{~nm}$ direct detection.

Bull. Chem. Soc. Ethiop. 2008, 22(1) 
(ii) Separation of the singly-charged species at $\mathrm{pH} 3.8$ and 7.0

The singly charged species examined $\left(\mathrm{Br}^{-}, \mathrm{I}^{-} \mathrm{NO}_{3}{ }^{-}, \mathrm{NO}_{2}{ }^{-}\right.$and $\left.\mathrm{SCN}^{-}\right)$are those of environmental, quality/safety control significance. Electropherograms obtained from a mixture of these inorganic anions is shown in Figure 2a, in which $\mathrm{Br}^{-}$and $\mathrm{I}^{-}$co-migrated in a BGE consisting only of formate buffer $(10 \mathrm{mM})$ at $\mathrm{pH} 3.8$.

It was observed that addition of $10 \mathrm{mM} \mathrm{Bu}_{4} \mathrm{~N}^{+}$successfully resolved $\mathrm{Br}^{-}$from I but worsened the resolution of $\mathrm{SCN}^{-}$and $\mathrm{NO}_{2}^{-}$. To improve the resolution of $\mathrm{SCN}^{-}$from $\mathrm{NO}_{2}^{-}$, cetyltrimethylammonium ion $\left(\mathrm{CTA}^{+}\right)$was used to act as both ion-pairing cation and eof modifier. However, the addition of $0.2 \mathrm{mM} \mathrm{CTA}^{+}$neither resolved $\mathrm{Br}^{-}-\mathrm{I}^{-}$nor $\mathrm{SCN}^{-}-\mathrm{NO}_{2}^{-}$pairs. $\mathrm{CTA}^{+}$significantly reduced the analysis time but poorly resolved the analytes. Both $\mathrm{Br}^{-}-\mathrm{I}^{-}$and $\mathrm{SCN}^{-}-\mathrm{NO}_{2}^{-}$pairs were resolved by the addition of $15 \mathrm{mM} \mathrm{Bu}_{4} \mathrm{~N}^{+}$in presence of $40 \% \mathrm{v} / \mathrm{v}$ ethanolic formate buffer (Figure 2b). The presence of ethanol increased the selectivity between the $\mathrm{SCN}^{-}$and $\mathrm{NO}_{2}^{-}$significantly. As shown in Figure $2 \mathrm{~b}$ there is a slight increase in migration time for all the anions, due to reduced eof arising from higher solvent viscosity and lower dielectric constant. The polarizable anions, $\mathrm{SCN}^{-}$and the $\mathrm{NO}_{2}^{-}$(protonated at this $\mathrm{pH}$ ), undergo stronger interaction with $\mathrm{Bu}_{4} \mathrm{~N}^{+}$in ethanolic solution [13] and are thus retained for much longer in the capillary. As a result, the peaks of the two anions are smaller and broader than those in Figure 2a.

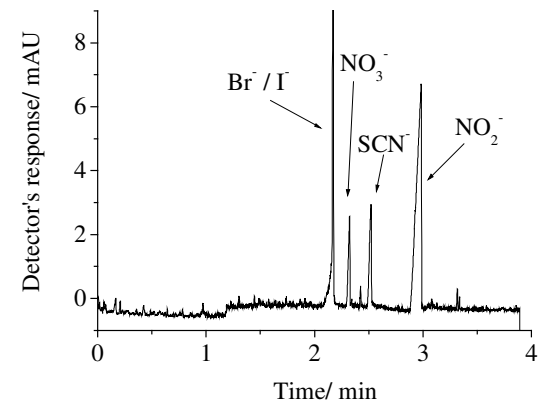

(a)

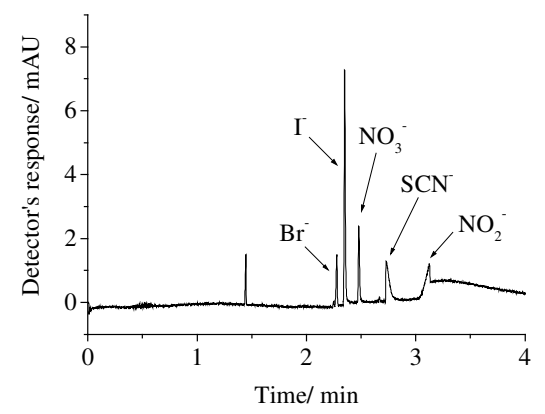

(b)

Figure 2. Separation of a mixture containing single-charged anions formate buffer $(10 \mathrm{mM})$ at $\mathrm{pH} 3.8$ upon association with $\mathrm{CTA}^{+}$and $\mathrm{Bu}_{4} \mathrm{~N}^{+}$in (a) buffer only and (b) $15 \mathrm{mM}$ $\mathrm{Bu}_{4} \mathrm{~N}^{+}$and $40 \%$ ethanol buffer. Conditions: As in Figure 1 .

The same separations were repeated at $\mathrm{pH} 7$ using phosphate buffer because some analyses

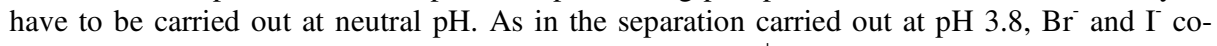
migrated (Figure 3a). At this $\mathrm{pH}$, addition of $10 \mathrm{mM} \mathrm{Bu}_{4} \mathrm{~N}^{+}$alone was sufficient to resolve all the analytes peaks (Figure 3b). Surprisingly a better baseline resolution was obtained at $\mathrm{pH} 7$ than at $\mathrm{pH}$ 3.8. However, because the separation time was longer than at $\mathrm{pH} 3.8$, an attempt was made to reduce the analysis time by using $\mathrm{CTA}^{+}$. Addition of $0.2 \mathrm{mM} \mathrm{CTA}^{+}$resolved $\mathrm{Br}^{-}$from I but led to co-migration of $\mathrm{I}^{-}$and $\mathrm{NO}_{2}{ }^{-}$(Figure $3 \mathrm{c}$ ). This indicates that $\mathrm{I}^{-}$associates more strongly with $\mathrm{CTA}^{+}$than either $\mathrm{Br}^{-}$or $\mathrm{NO}_{2}^{-}$, which is consistent with previous results [14] determined in aqueous solution at $\mathrm{pH} 3.8$. An attempt of using a combination of $\mathrm{CTA}^{+}(0.2 \mathrm{mM})$ and $\mathrm{Bu}_{4} \mathrm{~N}^{+}$ $(10 \mathrm{mM})$ did not produce an improvement of the $\mathrm{I}^{-}-\mathrm{NO}_{2}{ }^{-}$pair resolution (Figure $3 \mathrm{~d}$ ). 


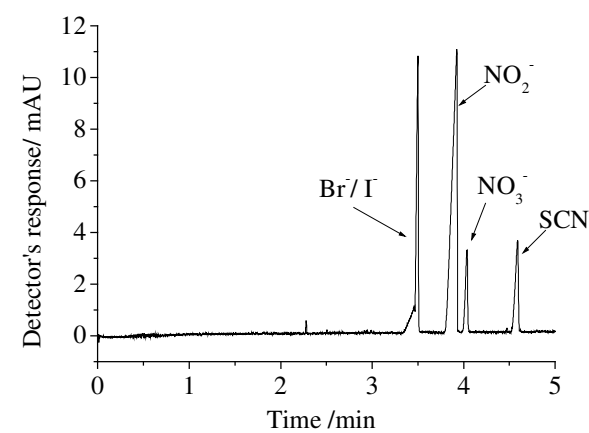

(a)

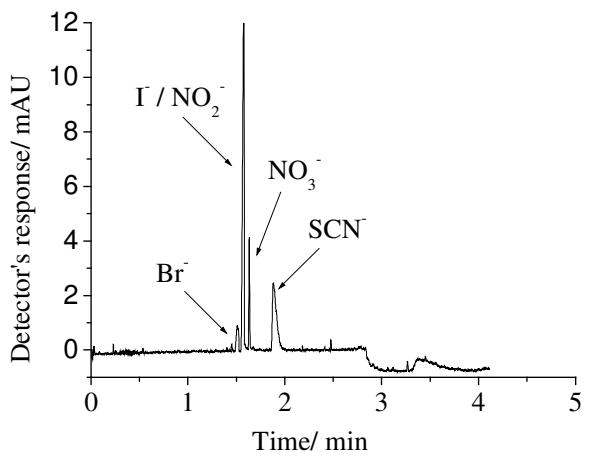

(c)

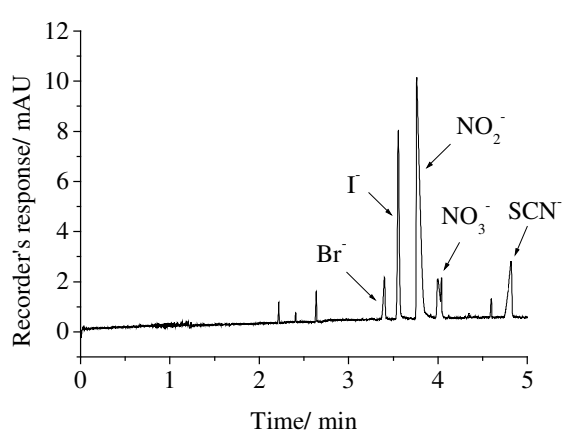

(b)

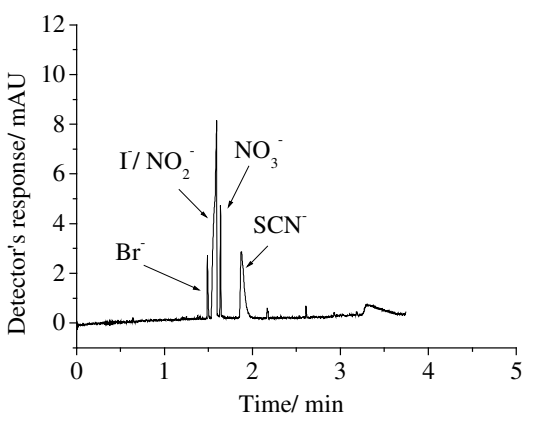

(d)

Figure 3. Separation of an mixture containing single-charged anions phosphate buffer $(10 \mathrm{mM})$ at $\mathrm{pH} 7.0$ upon association with $\mathrm{CTA}^{+}$and $\mathrm{Bu}_{4} \mathrm{~N}^{+}$in (a) buffer only, (b) $10 \mathrm{mM} \mathrm{Bu}_{4} \mathrm{~N}^{+}$, (c) $0.2 \mathrm{mM} \mathrm{CTA}^{+}$and (d) $0.2 \mathrm{mM} \mathrm{CTA}^{+}$and $10 \mathrm{mM} \mathrm{Bu}_{4} \mathrm{~N}^{+}$. Conditions: As in Figure 1 .

In general for this group of anions, using phosphate buffer $(\mathrm{pH} 7)$ produced a better resolution than using formate buffer $(\mathrm{pH} 3.8)$. However, the separation takes a longer time.

(b) Trace bromate/iodate determination: Application of weak ion association to bromate and iodate determination

FESI was adopted for online pre-concentration of bromate and iodate in water samples. Since stacking is favoured by low $\mathrm{pH}[25,26]$, formate and phosphate buffers were tested. While formate buffer would have been easy to optimize because of large amount of data collected in this study, it produced unstable baselines which not only drifted but also showed occasional dips. It was therefore abandoned because the baseline problems would complicate the quantification process. Phosphate buffer consisting of phosphoric acid and sodium dihydrogen phosphate was used. The background electrolyte also contained $\mathrm{Bu}_{4} \mathrm{~N}^{+}$as a pairing agent. In absence of the $\mathrm{Bu}_{4} \mathrm{~N}^{+}$, thiocyanate (internal standard) peak appeared close to or on the shoulder of the broad nitrate peak. In FESI, a water plug is injected prior to electrokinetic injection of the sample. As indicated in an earlier work [26], control of water plug and duration of sample are crucial in determining peak shapes. Longer water plug produced better stacking at the expense 
of peak shapes and analysis time. Shorter water plugs have an advantage of reducing the analysis time but stacking becomes poorer. Longer sample injections lead to increased introduction of the analyte but excessive introduction inevitably leads to sample overload. Higher separating potential have a tendency of reducing the analysis time but will also produce significant Joule heating effect for such fairly concentrated background electrolyte. Higher concentration of the background electrolytes ensured a more efficient stacking process. However, extremely high concentrations produced Joule heating effect as well as other inconsistencies like viscosity changes, etc.

The optimized conditions for bromate and iodate pre-concentration and separation are as follows:

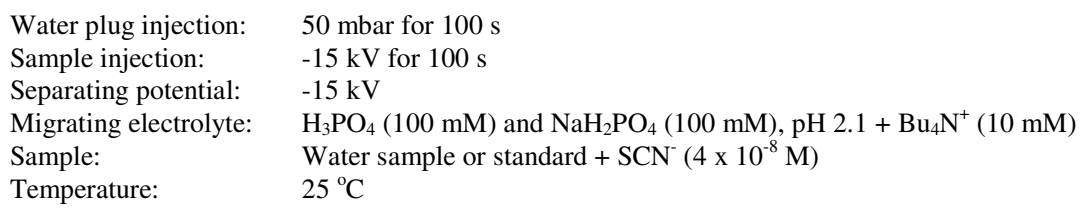

In calibration by the internal standard method, a series of standard solutions were prepared containing a constant concentration of thiocyanate and an increasing concentration of bromate and iodate $\left(2 \times 10^{-8} \mathrm{M}\right.$ to $\left.16 \times 10^{-8} \mathrm{M}\right)$. The ratios of peak areas of each analyte to thiocyanate's were plotted against corresponding ratios of concentration to yield a straight line calibration graph.

The analytical parameters of the method are summarized in Table 1. Since the samples were introduced electrokinetically, run to run reproducibility was poor in terms of peak area and height. To avoid such a poor precision, each run was done using a fresh sample solution. In order to minimize changes taking place in the electrolyte as a result of processes like electrolysis and wall adsorption, the background electrolyte was changed after every 7 to 8 runs and followed by capillary re-conditioning. While the precision in peak heights are comparable with those of a related work [22], these results showed an improvement in the precision of the migration time and peak areas of bromate. The limits of detection obtained are sufficient for a sensitive and reliable determination of bromate in drinking water according to EPA's MCL specification $(10 \mathrm{ppb})$.

Table 1. Analytical parameters of bromate and iodate determination method.

\begin{tabular}{|l|c|c|}
\hline Parameter & $\mathrm{BrO}_{3}{ }^{-}$ & $\mathrm{IO}_{3}{ }^{-}$ \\
\hline $\mathrm{LOD}(\mathrm{S} / \mathrm{N}=3)(\mathrm{M})$ & $7.8 \times 10^{-10}$ & $1.2 \times 10^{-9}$ \\
$(\mathrm{ppb})$ & 0.10 & 0.21 \\
& Relative standard deviations, RSD's (\%) \\
Migration time & 2.48 & 3.53 \\
Peak height & 5.07 & 4.02 \\
Corrected peak area & 5.97 & 6.21 \\
\hline
\end{tabular}

Analytical parameters based on $6 \times 10^{-8} \mathrm{M}$ for each anion in the standard.

A known amount of the internal standard was added to each sample and analyzed. Using the area ratios in the calibration graph, the amount of bromate and iodate present in the samples were determined. Figure 4 shows an electropherogram obtained upon spiking tap water with with $6 \times 10^{-8} \mathrm{M}$ iodate. Despite the long analysis time, it is still shorter than IC's average analysis time of $25 \mathrm{~min}$. The analysis time in this method can be further reduced to less than 8 min if the effective capillary length is decreased from $40 \mathrm{~cm}$ to $30 \mathrm{~cm}$, without any loss of 
efficiency. The amounts of the bromate and iodate contained in the four drinking water samples are presented in Table 2. Except for one sample of bottled water, which slightly exceeded the EPA's guideline for bromate content in water, all the water samples analyzed complied with the MCL of $10 \mathrm{ppb}$. Interestingly all water samples contained a significant amount of iodate, suggesting either a contamination by iodate during disinfection process or natural presence of iodide in the water samples.

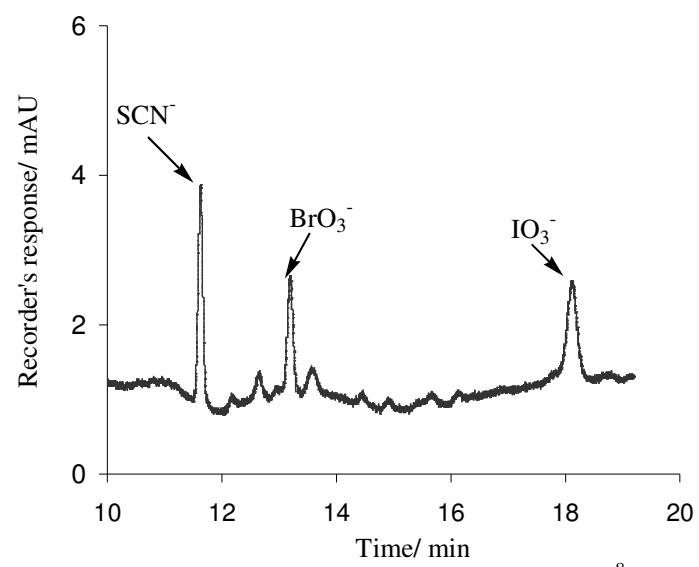

Figure 4. Electropherogram of tap water spiked with iodate $\left(6 \times 10^{-8} \mathrm{M}\right)$ and containing $\mathrm{SCN}^{-}(4$ x $\left.10^{-8} \mathrm{M}\right)$ as an internal standard. Conditions: water plug injection - 50 mbar for $100 \mathrm{~s}$; sample injection - electrokinetic $-15 \mathrm{kV}$ for $100 \mathrm{~s}$; separating potential: $-15 \mathrm{kV}$; detection: $200 \mathrm{~nm}$ direct detection.

Table 2. Bromate and iodate levels in drinking water.

\begin{tabular}{|c|c|c|c|}
\hline \multirow{2}{*}{\multicolumn{2}{|c|}{ Sample }} & \multicolumn{2}{|c|}{ Amount (ppb) } \\
\hline & & Bromate & Iodate \\
\hline \multicolumn{2}{|c|}{ Tap water (Analytical Chem. Laboratory) } & $6.6 \pm 0.6$ & $4.4 \pm 0.6$ \\
\hline \multirow{3}{*}{ Mineral water } & A & $6.1 \pm 0.8$ & $2.6 \pm 0.6$ \\
\hline & $\mathrm{B}$ & $5.6 \pm 0.4$ & $4.4 \pm 0.4$ \\
\hline & $\mathrm{C}$ & $12.9 \pm 0.8$ & $1.3 \pm 0.4$ \\
\hline
\end{tabular}

$n=6$, error: $2 \sigma(95 \%$ confidence limit).

\section{CONCLUSIONS}

Weak ion association can be utilized to separate co-migrating or closely migrating species. For the singly charged anions of environmental interest better resolution was obtained at $\mathrm{pH} 7$ than $\mathrm{pH}$ 3.8. Weak ion association was applied to the determination of bromate and iodate in several samples of drinking water. Trace, simultaneous CE determination of bromate and iodate in drinking water was done in this study for the first time. The limit of detection (LOD: $\mathrm{S} / \mathrm{N}=3$ ) for the bromate and iodate are 0.10 and $0.21 \mathrm{ppb}$, respectively. Upon further refinement to improve peak area and peak height reproducibility, the CE method can be a viable alternative to the recommended IC methods. Its advantages over IC include short analysis time, no need for sample pretreatment, simplicity, cheaper (no special post separation reagents required) and lack of interference. The results show that most of the drinking water samples analyzed complied with EPA's guideline for bromate level in water but also contain a significant amount of iodate ions. 
Use of ion association in separation of inorganic anions by capillary electrophoresis

\section{REFERENCES}

1. Smith, K.D.; McCord, B.R.; MacCrehan, W.A.; Mount, K.; Rowe, W.F. J. Forensic Sci. 1999, 44, 789.

2. Krawczeniuk, A.S.; Bravenec, V.A. J. Forensic Sci. 1998, 43, 738.

3. Hortin, G.L.; Dey, S.K.; Hall, M.B.; Robinson, C.A. J. Forensic Sci. 1999, 44, 1310.

4. Glatz, Z.; Nováková, S.; Štěrbová, H. J. Chromatogr. A 2001, 916, 273.

5. Soga, T.; Tajima, I.; Heiger, D.N. American Laboratory 2000, 32, 124.

6. Lucy, C.A. J. Chromatogr A. 1999, 850, 319.

7. Jimidar, M.; Hartmann, C.; Cousement, N.; Massart, D.L. J. Chromatogr. A 1995, 706, 479.

8. Röder, A.; Bachmann, K. J. Chromatogr. A 1995, 689, 305.

9. Tenberken, B.; Ebert, P.; Hartman, M.; Kibler, M.; Mainka, A.; Prokop, T.; Roder, A.; Bachmann, K. J. Chromatogr. A 1996, 745, 209.

10. Harrold, M.P.; Wojtusik, M.J.; Riviello, J.; Henson, P. J. Chromatogr. 1993, 640, 463.

11. Kimberly, I.R.; Lucy, C.A. J. Chromatogr. A 2002, 964, 213.

12. Shamsi, S.A.; Danielson, N.D. Anal. Chem. 1994, 66, 3757.

13. Mbuna, J.; Takayanagi, T.; Oshima, M.; Motomizu, S. Bull. Chem. Soc. Jpn. 2004, 77, 1465

14. Mbuna, J.; Takayanagi, T.; Oshima, M.; Motomizu, S. J. Chromatogr. A 2004, 1022, 191.

15. Motomizu, S.; Takayanagi, T. J. Chromatogr. A 1999, 853, 63.

16. Takayanagi, T.; Wada, E.; Motomizu, S. Analyst 1997, 122, 1387.

17. Takayanagi, T.; Motomizu, S. Anal. Sci. 2002, 18, 1021.

18. Kurokawa, Y.; Hayashi, Y.; Maekawa, A.; Takahashi, M.; Kokubo, T.; Odashima, S. J. Natl. Cancer Inst. 1983, 71, 965.

19. Kurokawa, Y.; Maekawa, A.; Takahashi, M.; Hayashi, Y. Environ. Health Perspect. 1990, 87, 309.

20. Gordon, G.; Kieffer, R.; Rosenblatt, D.H. The chemistry of chlorine dioxide in: Progress in Inorganic Chemistry, Vol. 15, Wiley-Interscience: New York; 1972.

21. Bolyard, M.; Fair, P.S.; Hautman, D.P. Environ. Sci. Technol. 1992, 26, 1663.

22. Haag, W.R.; Holgne, J. Environ. Sci. Technol. 1983, 17, 261.

23. USA Fed. Reg. 59, No. 145 1994, 38710.

24. Wagner, H.P.; Pepich, B.V.; Hautman, D.P.; Munch D.J. J. Chromatogr. A 2003, 1011, 89.

25. Kim, J.-B; Otsuka, K.; Terabe, S. J. Chromatogr. A 2002, 979, 131.

26. Quirino, J.P.; Shigeru, S. J. Chromatogr. A 1999, 850, 339. 